International Journal of Engineering \&Technology, $7(3.12)(2018) 526-530$
International Journal of Engineering \& Technology
Website: $w$ ww.sciencepubco.com/index.php/IJET
Research paper

\title{
IoT Enabled Solar Power Monitoring System
}

\author{
R.L.R. Lokesh Babu ${ }^{1}$, D Rambabu ${ }^{2}$, A. Rajesh Naidu ${ }^{3}$, R. D. Prasad ${ }^{4}$, P. Gopi Krishna ${ }^{5}$ \\ ${ }^{1,2,3,4}$ Department of Electronics and Communication Engineering, Ramachandra College of Engineering, \\ Eluru, Andhra Pradesh. \\ ${ }^{5}$ Departments of ECM, Koneru Lakshmaiah Education Foundation, Vaddeswaram, Guntur, Andhra Pradesh, India \\ *Corresponding Author Email: ${ }^{1}$ lalraj432@gmail.com, ${ }^{2}$ rambabu.rce@gmail.com, ${ }^{3}$ rajeshnaiduare@gmail.com, \\ ${ }^{4}$ durga.rajulapati@gmail.com, ${ }^{5}$ gopikrishna.popuri@gmail.com
}

\begin{abstract}
This paper proposes a solution and method to monitor the dust accumulated on the solar panels to get the maximum power from for effective utilization. Always the output power of the solar panel depends on the radiation reached to the solar cell. The system also displays the malfunctioned solar panels lists and whether the electrical appliance is working directly on the solar panels or the loads is on the battery. All the panels are connected, and sensors are directly connected to the central controller which monitor the panels and loads. By incorporating the IoT technology the data received from the panels and appliance are send to the cloud from through internet for the future use as well the remote user can monitor the parameters of the connected devices. The user can view the current, previous, and average parameters such as voltage, current, temperature and sun light using a graphical user interface GUI. The controller is programmed with predefined conditions with user alerts when it falls below the specified conditions. Node MCU is used as a controller.
\end{abstract}

Keywords: Internet of Things (IoT), NODE MCU, GSMA, PV, Solar panel, LCD, Things Speak.

\section{Introduction}

Internet of things (IoT) is playing a major and crucial role in the daily life of humans by enabling the connectivity of many and most of the physical devices through internet to exchange the data for monitoring and controlling the devices from a remote location, where are the devices becomes intelligent [1]. This technology can connect a wide range and varieties of things such as animals, humans, smart transport, smart grids, virtual power grids, smart cities, vehicles, heart monitoring systems, environmental sensing, shopping systems, automated homes, energy management, assistance for disabled and elderly individuals, cochlear implants, tracking of things, equipment manufacturing, agriculture, emergency monitoring systems, electronics tool collection systems, vehicle control etc. according to the survey there is a increase of $31 \%$ i,e 8.4 billion internet connected devices from 2016-2017. The connected device may increase to 30 billion by 2020 and which makes the business market around 7.1 trillion dollars by 2020 [2]. By using the IoT we can enable the machine to machine communication $\mathrm{M} 2 \mathrm{M}$ or device to device communication without human intervention.

In the modern life electricity became the important and essential part of the life. For any work now, a day we require electricity like lighting, heating, refrigeration, cooling, transportation systems what not all the home appliance works on electricity. In day to day life the consumption of electricity is increased but not decreased. To compete with the requirement of the public more and more electricity is to be generated and give to the end users. As the population increases the consumption also increases.

The power is generated in three methods generators, electro chemistry, photovoltaic effect.

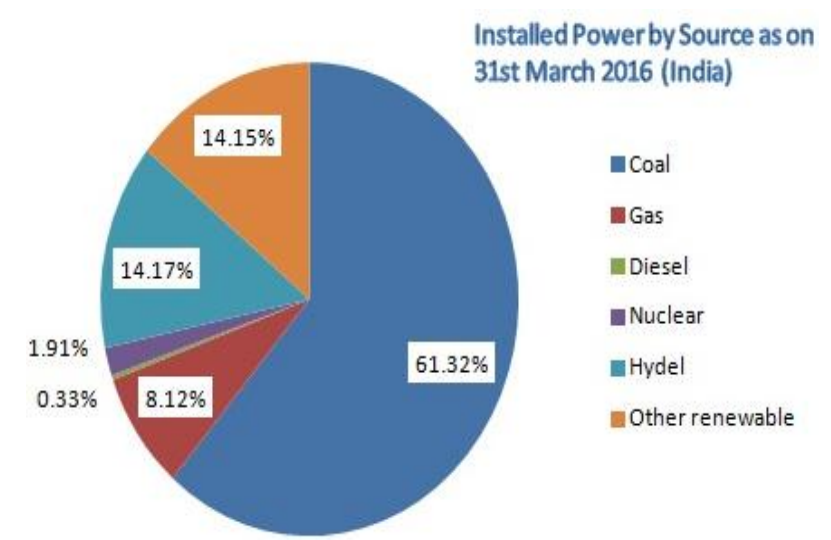

Fig. 1: The percentage of power sources installed

The electric generator is the most used form to generate the electricity which based on faraday's law of electromagnetic induction by transforming the mechanical energy into electrical energy. Storing the electricity in a battery is called electro chemistry which transforms the chemical energy to electrical energy. The other source to electricity is renewable energy which transforms the light energy into electrical energy which is known as photovoltaic effect we call this as solar energy. In this the electricity is generated from free, abundant sunlight.

The mechanically generated power is cheaper than compared with solar power to produce in large quantities due to of photovoltaic solar panels. In remote locations where there is no commercial power solar energy becomes the source for the home and other things. In the recent era the solar panels are deployed dramatically, and subsidies are given. Due the environmental conditions like global warming the all countries reduced 
production of electricity by burning the fossil fuels. A Typical solar module consists of $6 \times 10$ photovoltaic solar cells which can generate the power for residential applications. If requires the more power than more number of panels to installed. The panel produces DC output power in range of 100 to 365 Watts.

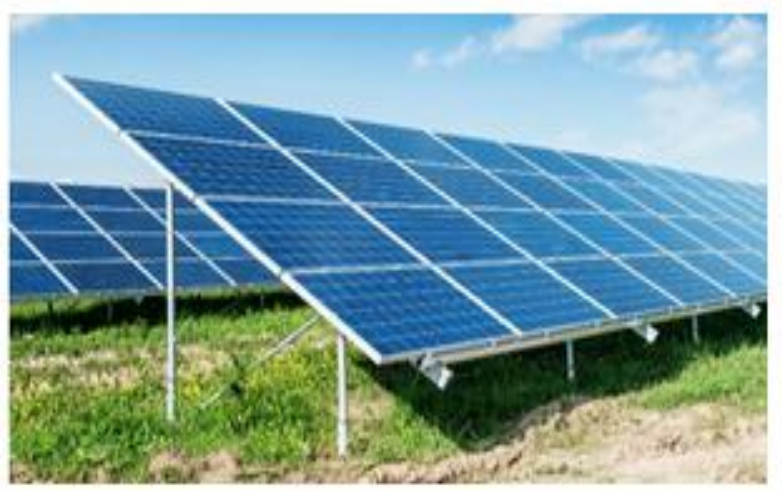

Fig. 2: Solar Panels

To produce huge electricity for the commercial and business purpose no of panels are placed in a array which are called as solar plants.

Always the output power of the solar panel depends on the radiation reached to the solar cell that convert into electric energy. if the dust is more on the panel then the less electricity is produced where the effectiveness of the solar panel decreases. To increase the efficiency of the solar panels some improvement must be done. In paper we propose a system that monitors the dust formed on the panels. Systems consists of a controller incorporated with Node MCU, LDR sensor. The controllers check the predefined conditions that are programmed and detects whether dust is from through the output voltage and give the alerts to the users or the maintenance in charge. It also uses the things speak cloud to show the received data from sensor and GUI to monitor [9].

\section{Literature of the Existing Method}

Many researchers had made many studies in this major problem and proved that $50 \%$ of the PV solar panels performance reduces by the dust accumulation on the cleaned panels.

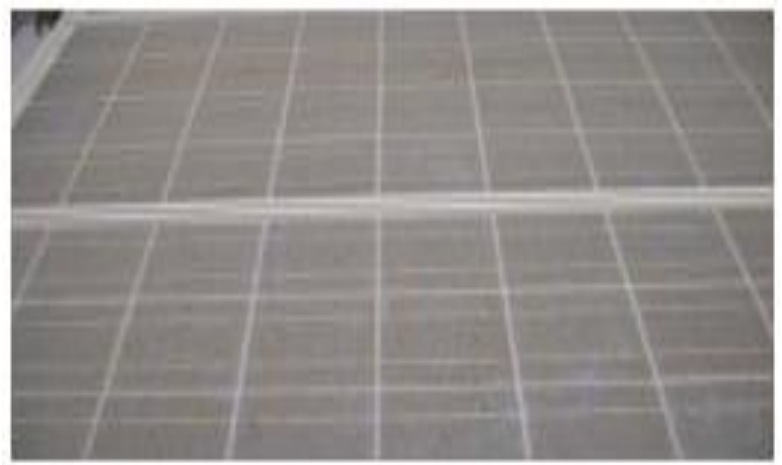

Fig. 3: Solar module covered by heavy layer due to dust accumulation before cleaning

The studies made on the effects that causes to the solar panel due dirt the by well-known organization in the world google of 1.6 MW solar plant in there California headquarters [3]. $4.7 \%$ average loss is recorded in the pioneer's investigations by impact of dust in the solar systems that is made by the authors Hottel e.l. [4]. The authors Salim et al made an investigation on dust accumulation and stated that there is a $32 \%$ reduction of solar power in a span of eight months in a solar village near Riyadh [5]. An experiment is conducted by the authors Dirk Goosen et. Al in [6] on the deposition of the dust particles which had affected the performance of the PV cells and investigated the airborne concentration and wind velocity effect caused by accumulation of dust. Author Garg of Roorkee made an experiment and discovered that panel would reduce $8 \%$ average transmittance by the accumulation of dirt on 45-degree tilted glass plate after a 10-day period [7]. Due to accumulation of dust on the panels it is observed that useful energy is reduced by $30 \%$. The common methods used to clean the dust is by spraying water on the panels with cleaning agent. Vibrating the panels with motors as the cell phone vibrates so that the dust goes off from the panels. The dust jumps off from the panels by creating a positive charge. By using a brush manual, we must clean the PV panels. Solar panel monitoring is important. It is vital that solar panels are monitored regularly in one way or another. You need to make sure they are operating correctly, and the system is generating as much as predicted. If you have solar panels installed, you should at the very least check the generation meter once a week and take a note of the reading [8]. And should go to the place of the panels arranged and note the readings every time. It is a manual checking procedure, always should go to the place of solar panel system arrangement to note down the readings. So, it is not possible to take readings all the time, whenever required should go to the place of system arrangement. And optimum power cannot be obtained due to no proper alignment of solar power.

\section{Proposed Method}

The main objective of this project is to get an optimum power output from the solar panels during dust is accumulated on it. Also, if there is any malfunctioning of the solar panels will be displayed on and we can also get information about whether the solar or battery connected for the loads. The system detects and alerts the user or the administrator when is fall below the predefine conditions, and display on the GUI. A solar panel is used that keeps monitoring the sunlight. Here different parameters like voltage, current and temperature are displayed on the LCD by using IOT technology.

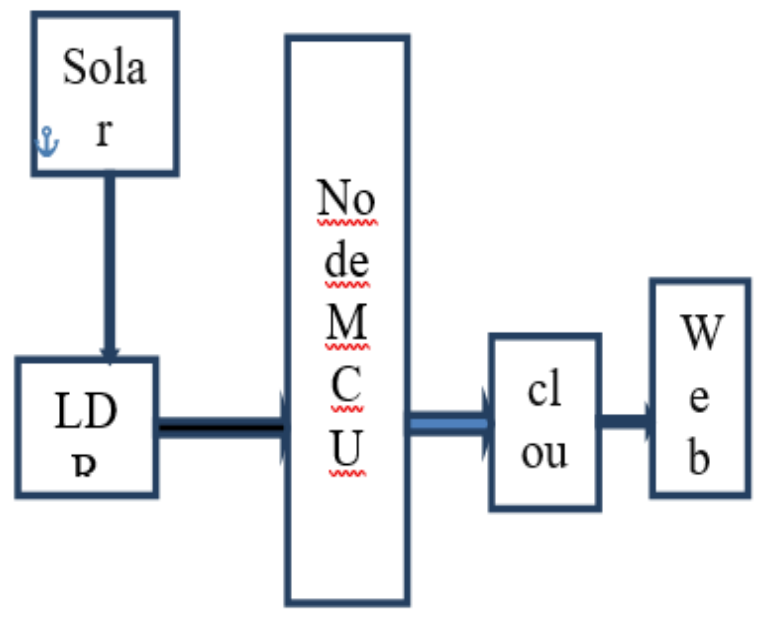

Fig. 4: Block diagram of proposed method

The above shown is the block diagram in figure 4 is the block diagram of the proposed method

\section{Hardware Implementation of the Proposed Method}



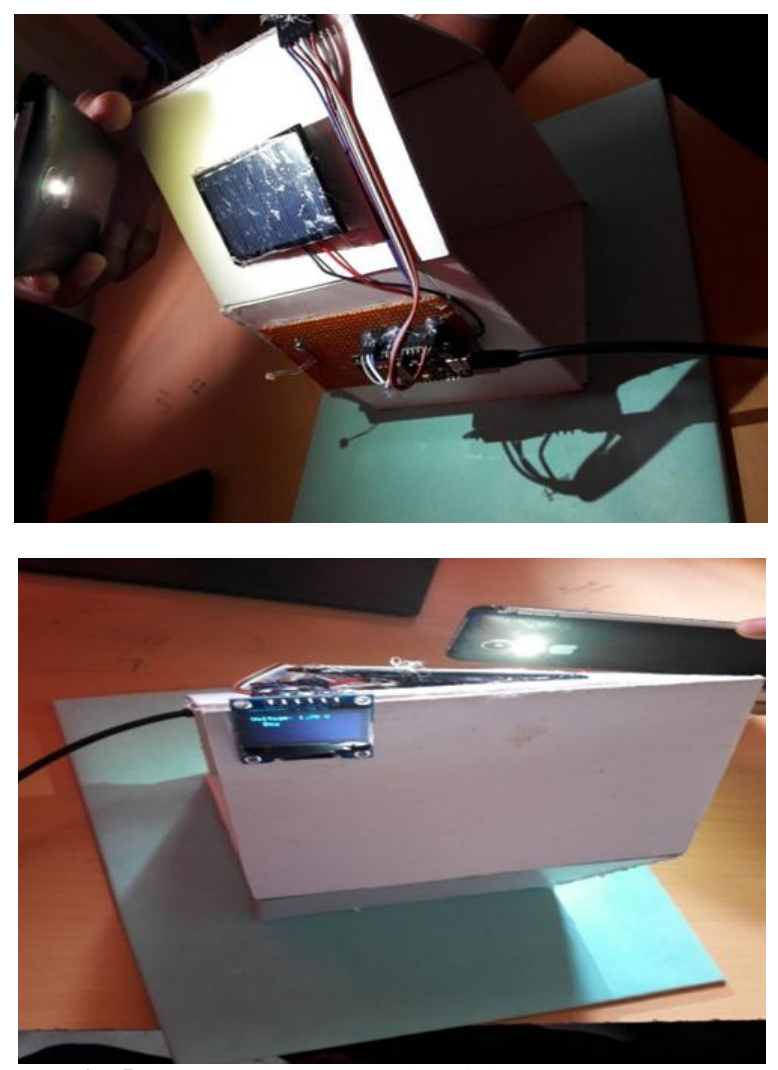

Fig. 5: Hardware implementation of the proposed method

The most conspicuous part of a residential solar power system is the solar panels. Thin-film semiconductor or crystalline silicon is used make the $\mathrm{P} V$ solar cell for many of the residential applications. These photovoltaic (PV) devices contain semiconductors that generate electricity directly from sunlight. The electrical devices are powered, or it is send to the grid when electrons are made free by solar energy in these materials. One of the most important aspects of getting your solar panels to produce electrical energy at optimum efficiency is keeping them in full and direct sunlight. DC voltage current is generated when the Photovoltaic solar panels are exposed directly to the sunlight Solar panels generate the DC were the home appliance works on the AC power, so the output of the panels is given as input to the invertor. All the appliance works through the invertor. The invertor consists of a battery. The battery gets charges when the appliance is not in used and gets discharged when requires the supply. Solar monitoring systems will track the amount of electricity your solar panels have generated and contributed to the power grid.

For the sensing the light we have used a light dependent resistor is component varies the resistance with the light intensity that fall on it and can different a night and a day There are many potential ways of monitoring solar panels. There are high tech solutions which upload data continuously to a web portal which allows you to monitor your systems performance from anywhere in the world. In this proposed system we have an open source cloud[10] platform application think speak is used. Which retrieves and stores the data from the sensor or the things connected to the systems through internet that uses hypertext transfer protocol (HTTP) from the local network to the cloud. It updates all the data logs received from the sensors, tracking location applications, and the status application giving to the users and taken from the users. To use this the user has create an account which contains different channels for monitoring of different parameters in the system or in the monitoring the paraments in a remote device. This cloud enables the administrator or the user to visualize the data in graphical representation. With internet-based monitoring, energy output data is transferred to a router, making it available through an online interface. The main advantage of systems like these is that your solar panel output information is readily available anywhere you can get an internet connection

The node MCU acts as a key processing element for the proposed system as shown in figure 4 and figure 5 which is developed by ESP8266 open source community of micro-controller on single board that can be programmed using the Arduino IDE having a RAM size of $128 \mathrm{Kbytes}$ and program storage capacity of 4 Mega Bytes. It can be powered by a USB cable, having a operating voltage of 3.3 to 5 volts and an in built Wi-Fi SoC Architecture. The figure 6 show that Node MCU

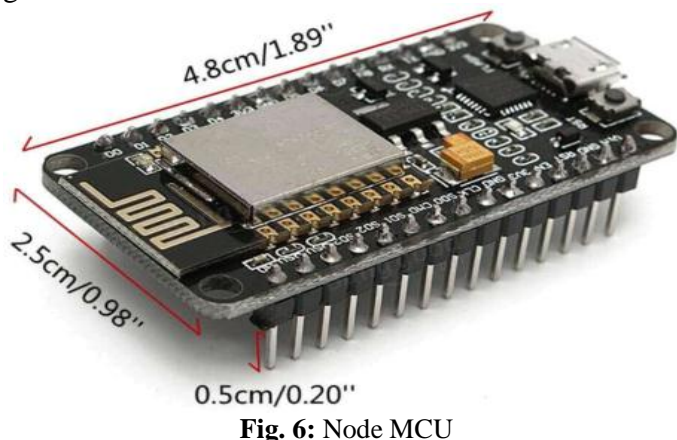

Solar Panel

The electricity generated by capturing the sun light is called as solar energy which is used for business and home purpose. The natural nuclear reactor is sun which releases the energy with tiny packets called photons. The atoms lose the electrons when the photons hit the solar cells. A solar panel is made of multiple panels that wired together, more electricity is generated by the more panels we deploy. Silicon like semiconductors are used to make the PV photovoltaic solar panels as shown in figure 7. Direct Current is generated by the solar panels. Most of the electrical appliance works on AC supply can AC can be less expensive for transmit to long distances.

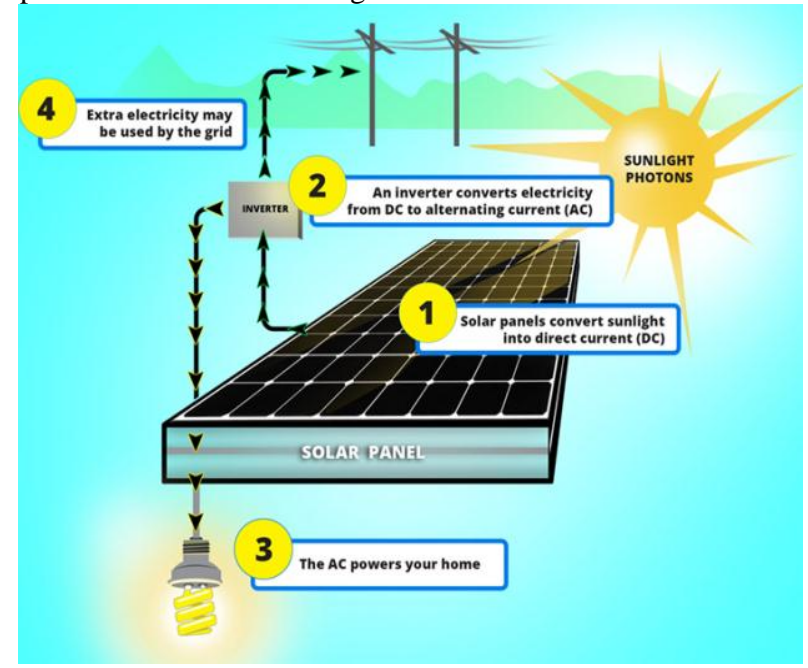

Fig. 7: Solar Energy Conversion

\section{LDR}

Photo conductivity is the main working principle of a LDR or light dependent resistor. All the electrons in the semiconductor of the valance band excites when the light or photos fall on the resistor. When the light falls on the LDR resistance gets decreased and increase in the dark or called as dark resistance. Basing on the materials the LDR's are classified in to two types Intrinsic Photo Resistor and Extrinsic photo resistor. 


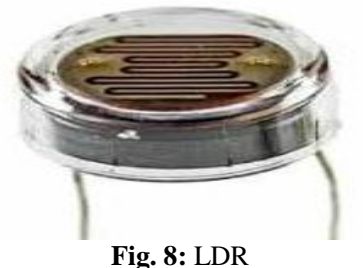

Fig. 8: LDR

\section{Things Speak Cloud setup}

An open source cloud platform application think speak is used. Which retrieves and stores the data from the sensor or the things connected to the systems through internet that uses hypertext transfer protocol (HTTP) from the local network to the cloud. It updates all the data logs received from the sensors, tracking location applications, and the status application giving to the users and taken from the users. To use this the user has create an account which contains different channels for monitoring of different parameters in the system or in the monitoring the paraments in a remote device. This cloud enables the administrator or the user to visualize the data in graphical representation. With internet-based monitoring, energy output data is transferred to a router, making it available through an online interface. The main advantage of systems like these is that your solar panel output information is readily available anywhere you can get an internet connection

\section{Results \& Conclusion}

In this project IoT based system is designed to get an optimum power output from the solar panels during dust is accumulated on it. And, a monitoring system is designed for there is any malfunctioning of the solar panels will be displayed on and we can also get information about whether the solar or battery connected for the loads. It now displays these parameters as shown in figure 9 to the user using an effective GUI and alerts user when the output falls below specific limits. A solar panel is used that keeps monitoring the sunlight. Here different parameters like voltage, current and temperature are displayed on the LCD by using IOT technology. Now we are getting only information we can see it in cloud but in future we can control whole system through IoT which Distant is a way.

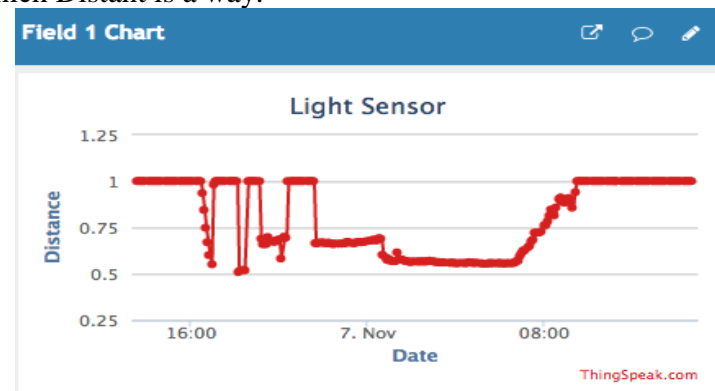

Fig. 9: LDR values transmitted from the working location to the cloud

\section{References}

[1] P. Gopi Krishna et. al. "Design and development of bi-directiona smart IoT gateway with interoperability for heterogeneous devices" International Journal of Engineering \& Technology, 7 (2.8) (2018) 109-114

[2] Nordrum, Amy (18 August 2016). "Popular Internet of Things Forecast of 50 Billion Devices by 2020 Is Outdated". IEEE

[3] M. Moon. (2009) Google Studies How Dirt Affects Solar Panel Efficiency. PC Magazine: Good Clean Tech. Available: www.goodcleantech.com/2009/08/google_studies_how_dirt_affect. php
[4] M. C. Hottel and B. B. Woertz, "Performance of flat plate solar heat collectors," ASME Trans., vol. 64, pp. 91-104, 1942.

[5] Salim, F. Huraib, and N. Eugenio, " PV power-study of system options and optimization," in Proceedings of the 8th European PV Solar Energy Conference, Florence, Italy, 1988.

[6] D. Goossens and E. V. Kerschaever, "Aeolian dust deposition on photovoltaic solar cells: the effects of wind velocity and airborne dust concentration on cell performance," Solar Energy, vol. 66, pp. 277-289, 1999. World

[7] H. P. Garg, "Effect of dirt on transparent covers in flat-plate solar energy collectors," Solar Energy, vol. 15, pp. 299-302, 1973

[8] P. Gopi Krishna et. al. "Design and development of smart energy meter for effective use of electricity in IoT applications" International Journal of Engineering \& Technology, 7 (2.8) (2018) 115-119

[9] P. Gopi Krishna et. al "Design and development of bi-directional IoT gateway using ZigBee and Wi-Fi technologies with MQTT protocol" International Journal of Engineering \& Technology, 7 (2.8) (2018) 125-129

[10] Agora Energiewende (2016), “Agorameter", website, www.agoraenergiewende.de/en/topics//Produkt/produkt/76/Agorameter/ (accessed 23 May 2016).

[11] BNEF (Bloomberg New Energy Finance) (2016), Renewable Energy Projects dataset, Bloomberg New Energy Finance website, (accessed on 15 April 2016).

[12] CENACE (2016), "Subastas Largo Plazo" [Long Term Auctions], website,

www.cenace.gob.mx/Paginas/Publicas/MercadoOperacion/Subastas LP.aspx. CSIR (Council for Scientific and Industrial Research) CSIR (2015), “

[13] Financial benefits of renewables in South Africa in 2015", CSIR Energy Centre, Council for Scientific and Industrial Research, Pretoria. CSIR (2016), "Wind and Solar PV Resource Aggregation Study for South Africa", CSIR Energy Centre, Council for Scientific and Industrial Research, Pretoria, http://www.csir.co.za/Energy_Centre/ wind_solarpv.html.

[14] DOE (2015), State of Renewable Energy in South Africa, Department of Energy, Pretoria, www.gov.za/sites/www.gov.za/files/State\%20of\%20Renewable $\% 2$ 0Energy\%20in\%20South\%2 0Africa_s.pdf (accessed 14 April 2016).

[15] DOE (2011), "Integrated resource plan for electricity 2010-2030", Department of Energy, 25 March 2011. DEA (Department of Environmental Affairs) (2016), "Cabinet approves gazetting of Renewable Energy Development Zones", website, www.environment.gov.za/ mediarelease/cabinet_gazetting_redz (accessed 14 April 2016).

[16] Efkm (2011), "Energy strategy 2050 - from coal, oil and gas to green energy", Danish Ministry of Climate and Energy on behalf of the Danish Government, Copenhagen, http://www.efkm.dk/sites/kebmin.dk/files/news/from-coal-oil-andgas-togreenenergy/Energy\%20Strategy\%202050\%20web.pdf (accessed 13 May 2016).

[17] Energinet.dk (2016), "New record-breaking year for Danish wind power", http://energinet.dk/EN/El/Nyheder/Sider/Danskvindstroem-slaar-igen-rekord-42- procent.aspx

[18] IEA (International Energy Agency) (2016a), System Integration of Renewables: Implications for Electricity Security, OECD/IEA, Paris

[19] IEA (2016b), RE-powering Markets: Market Design and Regulation during the Transition to lowCarbon Power Systems, OECD/IEA, Paris.

[20] Shaik Razia, P.Swathi Pryathyusha, N.Vamsi Krishna "A Comparative study of machine learning algorithms on thyroid disease prediction" International Journal of Engineering and Technology(UAE), ISSN No: 2227-524X, Vol No: 7, Issue No: 2.8, Page No: 315-319, March 2018.

[21] SHAIK RAZIA, P.Swathi Pryathyusha "A REVIEW ON DISEASE DIAGNOSIS USING MACHINE LEARNING TECHNIQUES" IJPAM (International Journal of Pure and Applied Mathematics), ISSN: 1311-8080 (printed version); ISSN: 1314-3395 (on-line version), Volume 117, No. 16, 79-85, 2017.

[22] SHAIK RAZIA, Manne Niharika "The Analysis of Data Representation Techniques for Early Prediction of Breast Cancer" IJPAM (International Journal of Pure and Applied Mathematics), ISSN: 1311-8080, ISSN: 1314-3395, volume 115, Issue: 6 , page no: 177-183, 2017.

[23] SHAIK RAZIA, M.R.Narasingarao, "Development and Analysis of Support Vector Machine Techniques for Early Prediction of Breast 
Cancer and Thyroid" JARDCS (Journal of Advanced Research in Dynamical and Control Systems), ISSN: 1943-023X, Vol.9.Sp.Issue:6 page no: 869-878, 2017.

[24] Avinash Yadlapati, Dr. Hari Kishore Kakarla, "An Advanced AXI Protocol Verification using Verilog HDL", Wulfenia Journal, ISSN: 1561-882X, Volume 22, Number 4, pp. 307-314, April 2015

[25] P Ramakrishna, K. Hari Kishore, "Design of Low Power 10GS/s 6Bit DAC using CMOS Technology "International Journal of Engineering and Technology(UAE), ISSN No: 2227-524X, Vol No: 7, Issue No: 1.5, Page No: 226-229, January 2018.

[26] A Murali, K. Hari Kishore, "Efficient and High Speed Key Independent AES Based Authenticated Encryption Architecture using FPGAs "International Journal of Engineering and Technology(UAE), ISSN No: 2227-524X, Vol No: 7, Issue No: 1.5, Page No: 230-233, January 2018

[27] G.S.Spandana, K Hari Kishore "A Contemporary Approach For Fault Diagnosis In Testable Reversible Circuits By Employing The CNT Gate Library" International Journal of Pure and Applied Mathematics, ISSN No: 1314-3395, Vol No: 115, Issue No: 7, Page No: 537-542, September 2017.

[28] K Hari Kishore, CVRN Aswin Kumar, T Vijay Srinivas, GV Govardhan, Ch Naga Pavan Kumar, R Venkatesh "Design and Analysis of High Efficient UART on Spartran-6 and Virtex-7 Devices", International Journal of Applied Engineering Research, ISSN 0973-4562, Volume 10, Number 09 , pp. 23043-23052, June 2015 .

[29] K Bindu Bhargavi, K Hari Kishore "Low Power BIST on Memory Interface Logic", International Journal of Applied Engineering Research, ISSN 0973-4562, Volume 10, Number 08 , pp. 21079 21090, May 2015

[30] Korraprolu Brahma Reddy, K Hari Kishore, “A Mixed Approach for Power Dissipation Reduction in Nanometer CMOS VLSI circuits", International Journal of Applied Engineering Research, ISSN 0973-4562 Volume 9, Number 18 , pp. 5141-5148, July 2014

[31] Nidamanuri Sai Charan, Kakarla Hari Kishore "Reorganization of Delay Faults in Cluster Based FPGA Using BIST" Indian Journa of Science and Technology, ISSN No: 0974-6846, Vol No.9, Issue No.28, page: $1-7$, July 2016

[32] Sravya Kante, Hari Kishore Kakarla, Avinash Yadlapati,"Design and Verification of AMBA AHB-Lite protocol using Verilog HDL" International Journal of Engineering and Technology, E-ISSN No: 0975-4024, Vol No.8, Issue No.2, Page:734-741, May 2016.

[33] Bandlamoodi Sravani, K Hari Kishore, "An FPGA Implementation of Phase Locked Loop (PLL)", International Journal of Applied Engineering Research, ISSN 0973-4562, Volume 10, Number 14 , pp. 34137-34139, August 2015

[34] Avinash Yadlapati, Kakarla Hari Kishore,"Constrained Level Validation of Serial Peripheral Interface Protocol", Proceedings of the First International Conference on SCI 2016, Volume 1, Smart Computing and Informatics, Smart Innovation, Systems and Technologies 77, ISSN No: 2190-3018, ISBN: 978-981-10-5544-7, Chapter No: 77, pp. 743-753, $25^{\text {th }}$ December 2017.

[35] P Kiran Kumar, P Prasad Rao, Kakarla Hari Kishore, "Optima Design of Reversible Parity Preserving New Full Adder / Full Subtractor", IEEE SPONSORED 3rd INTERNATIONAL CONFERENCE ON ELECTRONICS AND COMMUNICATION SYSTEMS (ICECS 2016), pp. $3465-3470,25^{\text {th }}$ and $26^{\text {th }}$ February 2016.

[36] Y Avinash, K Hari Kishore ''Designing Asynchronous FIFO for Low Power DFT Implementation', International Journal of Pure and Applied Mathematics, ISSN No: 1314-3395, Vol No: 115, Issue No: 8, Page No: 561-566, September 2017

[37] Mahesh Mudavath and K Hari Kishore "Design of RF Front End CMOS Cascade CS Low Noise Amplifier on 65nm Technology Process" International Journal of Pure and Applied Mathematics, ISSN No: 1314-3395, Vol No: 115, Issue No: 7, Page No: 417-422, September 2017

[38] P. Sahithi K Hari Kishore, E Raghuveera, P. Gopi Krishna "DESIGN OF VOLTAGE LEVEL SHIFTER FOR POWEREFFICIENT APPLICATIONS USING 45nm TECHNOLOGY" International Journal of Engineering and Technology(UAE), ISSN No: 2227-524X, Vol No: 7, Issue No: 2.8, Page No: 103-108, March 2018.

[39] N Bala Dastagiri K Hari Kishore "A 14-bit 10kS/s Power Efficient $65 \mathrm{~nm}$ SAR ADC for Cardiac Implantable Medical Devices" International Journal of Engineering and Technology (UAE), ISSN No: 2227-524X, Vol No: 7, Issue No: 2.8, Page No: 34-39, March 2018 .
[40] Meka Bharadwaj, Hari Kishore "Enhanced Launch-Off-Capture Testing Using BIST Designs" Journal of Engineering and Applied Sciences, ISSN No: 1816-949X, Vol No.12, Issue No.3, page: 636643, April 2017.

[41] P Bala Gopal, K Hari Kishore, R.R Kalyan Venkatesh, P Harinath Mandalapu "An FPGA Implementation of On Chip UART Testing with BIST Techniques", International Journal of Applied Engineering Research, ISSN 0973-4562, Volume 10, Number 14 pp. 34047-34051, August 2015.

[42] A Murali, K Hari Kishore, D Venkat Reddy "Integrating FPGAs with Trigger Circuitry Core System Insertions for Observability in Debugging Process" Journal of Engineering and Applied Sciences, ISSN No: 1816-949X, Vol No.11, Issue No.12, page: 2643-2650, December 2016.

[43] Mahesh Mudavath, K Hari Kishore, D Venkat Reddy "Design of CMOS RF Front-End of Low Noise Amplifier for LTE System Applications Integrating FPGAs" Asian Journal of Information Technology, ISSN No: 1682-3915, Vol No.15, Issue No.20, page: 4040-4047, December 2016.

[44] N Bala Dastagiri, Kakarla Hari Kishore "Reduction of Kickback Noise in Latched Comparators for Cardiac IMDs" Indian Journal of Science and Technology, ISSN No: 0974-6846, Vol No.9, Issue No.43, Page: 1-6, November 2016.

[45] S Nazeer Hussain, K Hari Kishore "Computational Optimization of Placement and Routing using Genetic Algorithm" Indian Journal of Science and Technology, ISSN No: 0974-6846, Vol No.9, Issue No.47, page: 1-4, December 2016.

[46] N Bala Dastagiri, K Hari Kishore "Analysis of Low Power Low Kickback Noise in Dynamic Comparators in Pacemakers" Indian Journal of Science and Technology, ISSN No: 0974-6846, Vol No.9, Issue No.44, page: 1-4, November 2016. 